\title{
THE TREATMENT OF ACUTE LEUKAEMIA IN ADULTS WITH CYCLOPHOSPHAMIDE
}

\author{
M. J. MeYNELl, M.D., F.R.C.P. \\ C. G. Parsons, M.D., F.R.C.P.
}

United Birmingham Hospitals.

THIS paper records the results of using cyclophosphamide to treat 7 adults with acute leukaemia. The drug is inert until nitrogen mustard is released by the action of enzymes in tumour cells and in the liver. Consequently it may be administered by any route without causing irritation or tissue damage. Toxicity is not a striking feature and, although nausea, alopecia and haemorrhagic cystitis have been reported, no abnormal reactions were observed in our patients. A fall in the polymorphonuclear count gives early warning of overdosage and occurs before platelets or red cells are affected.

Cyclophosphamide is supplied in two forms: $50 \mathrm{mg}$. tablets for oral use, and ampoules containing $100 \mathrm{mg}$. of powder which, after being dissolved in $5 \mathrm{ml}$. of sterile water, is used for parenteral administration. The recommended dose is $2.5 \mathrm{mg}$. $/ \mathrm{kg}$. Two patients were given intravenous treatment for the first few days; 2 patients had $100 \mathrm{mg}$. daily by mouth for two months, after which the dose was halved; the remaining patients took $50 \mathrm{mg}$. daily, by mouth. In addition blood transfusions have been given when necessary. Steroids and antibiotics have been administered routinely, together with Nystatin to prevent intestinal moniliasis and yeast granuloma of the liver (Lannigan and Meynell, 1959). Details of treatment are included in the illustrations.

\section{Case Reports}

\section{Case no. 1}

D.W.E. Male. Age 45. Acute monocytic leukaemia (Schilling).

Malaise, pyrexia and recurrent stomatitis for 8 months. Swollen gums, generalised lymphadenopathy, enlarged liver and spleen, diffuse maculopapular rash affecting especially inner aspect of arms and legs for a few days.

Investigations: Hb. 4.6 g. $/ 100 \mathrm{ml}$., WBC 3,400/cu. mm. (38\% monocytes), platelets $199,000 / \mathrm{cu}$. $\mathrm{mm}$. Sternal marrow hypercellular with $41 \%$ primitive cells of monocytic series.

Treatment: 6 pints blood, cyclophosphamide 200 $\mathrm{mg}$./day orally, prednisone $40 \mathrm{mg}$./day for 11 days. Dose then reduced to $100 \mathrm{mg}$. and $20 \mathrm{mg}$. respectively.
Progress: Rapid improvement, gained weight, returned to work. Felt so well that he stopped treatment after 4 months but did not inform doctor. After a further 10 weeks noticed lassitude, developed boils. White count 68,000 per cu. $\mathrm{mm}$. No response to second course of treatment. Death 7 months after diagnosis.

\section{Case no. 2}

E.T. Male. Age 49. Acute monocytic leukaemia (Schilling).

Progressive weakness, minor sepsis and sore throat. Enlarged liver and spleen, pharyngeal thrush.

Investigations: Hb. 8.0 g./100 ml., WBC 45,000/ cu. mm. (71\% monocytes), platelets $128,000 / \mathrm{cu}$. $\mathrm{mm}$.

Treatment: 4 pints blood, cyclophosphamide 100 mg./day orally, prednisone $40 \mathrm{mg}$./day.

Progress: Much better after a week, returned to work. After 3 months good health, developed lassitude and fever. White count 74,000/cu. mm. $80 \%$ monocytic series. Rapidly increasing white cell count. Death 4 months after diagnosis.

\section{Case no. 3}

L.B. Female. Age 49. Acute myeloblastic leukaemia. Under treatment for diabetes mellitus (chlorpropamide) for 4 months. Bruising and epistaxis for 3 days. Purpura on legs, large spleen.

Investigations: Hb. $10.2 \mathrm{~g} . / 100 \mathrm{mi}$., WBC 4,000/ cu. mm. (36 per cent myeloblasts), platelets 30,000/ cu. mm. Sternal marrow hypercellular with $51 \%$ myeloblasts.

Treatment: 4 pints blood, cyclophosphamide 50 $\mathrm{mg}$./day orally, prednisone $30 \mathrm{mg}$./day, lente insulin. Progress: Discharged after 3 weeks much improved. Three months later Hb. 13.9 g./100 ml., WBC 5,300/ cu. $\mathrm{mm}$. (3\% myeloblasts), platelets $146,000 / \mathrm{cu}$. mm. At end of fourth month developed purpura and pain in chest. WBC $4,000 / \mathrm{cu}$. mm. (11\% myeloblasts), platelets $30,000 / \mathrm{cu}$. mm. Death 5 months after diagnosis.

Necropsy: Bronchopneumonia, enlarged liver and spleen, purpura throughout viscera. Acute myeloblastic anaemia confirmed by microscopy.

\section{Case no. 4}

D.W. Female. Age 44. Acute myeloblastic leukaemia. Painful leg for 4 months, sore throat and fever for a few days. Enlarged liver and spleen.

Investigations: Hib. 7.4 g./100 ml., WBC 2,600/cu. $\mathrm{mm}$. ( $20 \%$ myeloblasts). Sternal marrow hypercellular with $54 \%$ myeloblasts and $14 \%$ premyelocytes. 
FIG. 1.
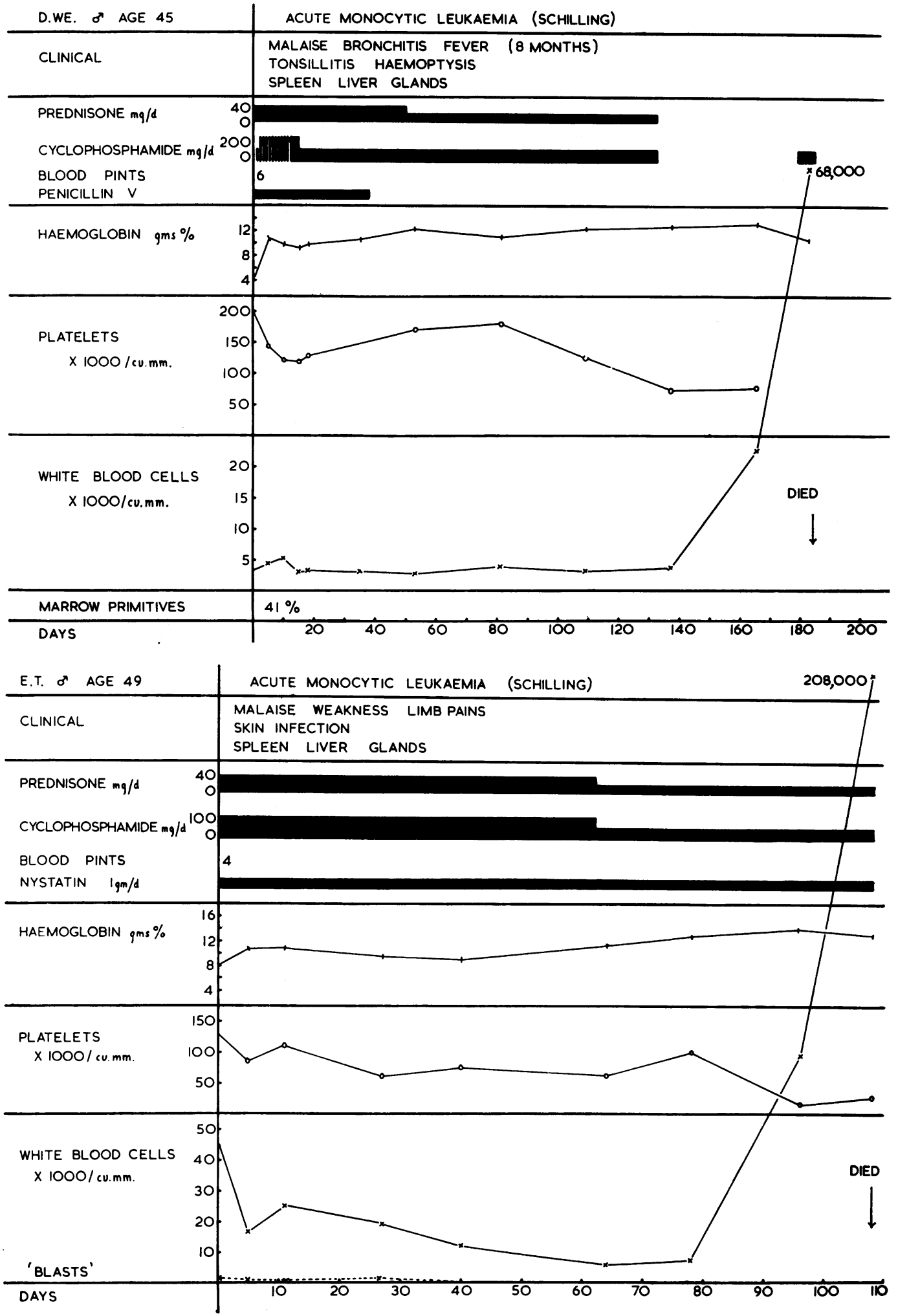

FIG. 2. 
FIG. 3.

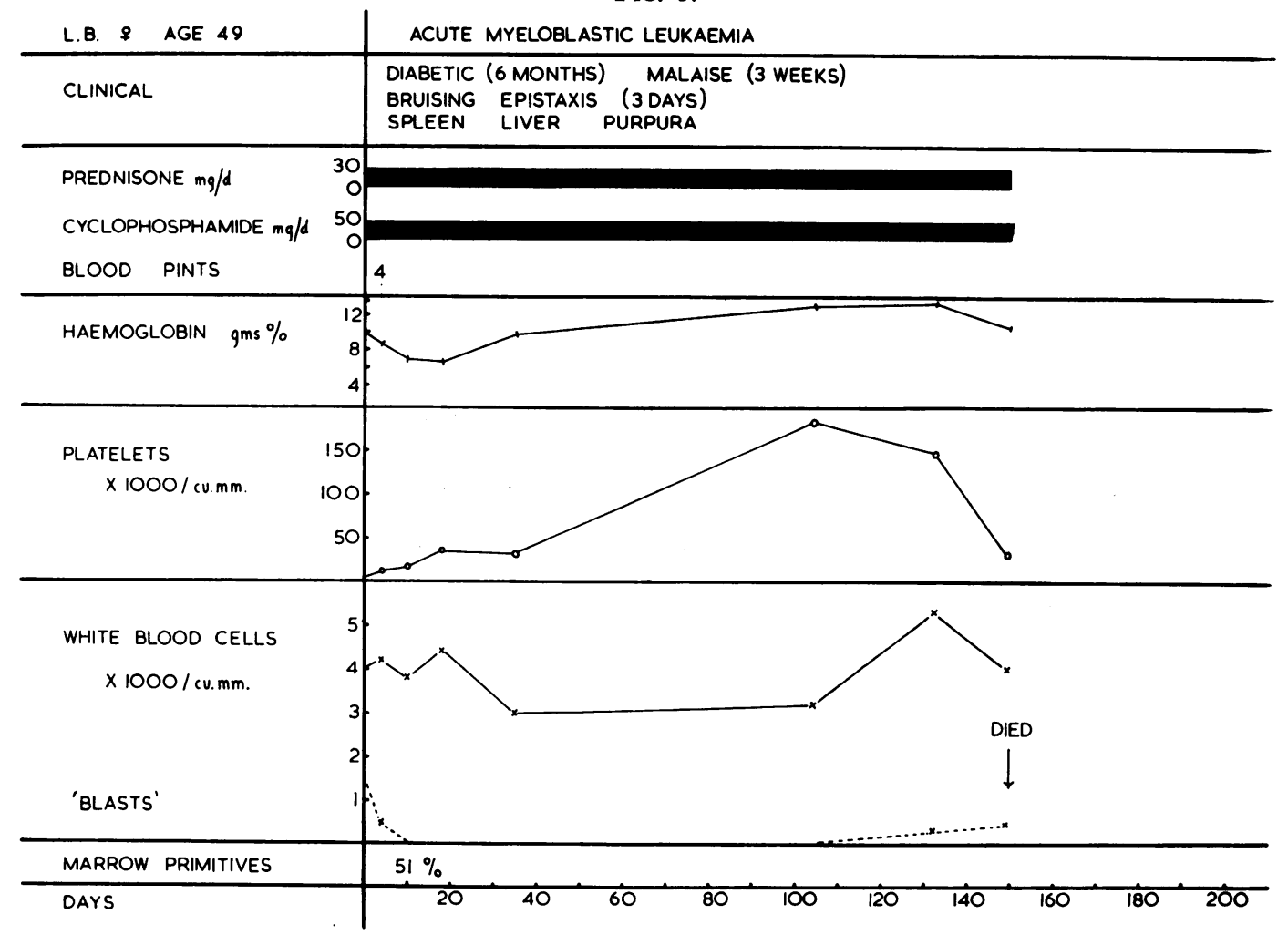

Treatment: 12 pints blood, cyclophosphamide 4 doses of $200 \mathrm{mg}$. intravenously, prednisone $60 \mathrm{mg}$. daily, tetracycline $250 \mathrm{mg}$. 4 times daily.

Progress: No improvement in general condition or blood picture. Death 3 weeks after diagnosis.

Necropsy: Acute myeloblastic leukaemia, with striking proliferation of megakaryocytes.

\section{Case no. 5}

I.L. Male. Age 69. Acute myeloblastic leukaemia. Anorexia and loss of weight, chest pain and dyspnoea on exertion for several weeks. No enlargement of liver or spleen, extensive bruising of skin and of floor of mouth.

Investigations: Hb. 8.2 g. $/ 100 \mathrm{ml}$, WBC 3,400/cu. mm. (30\% myeloblasts), platelets $42,000 / \mathrm{cu}$. mm. Sternal marrow hypercellular with $40 \%$ primitive myeloid cells.

Treatment: 4 pints blood, cyclophosphamide 50 mg./day orally, ampicillin 1.g. daily.

Progress: Discharged, greatly improved, after 5 days, but after 1 month recurrence of chest pain. ECG showed pattern of anterior myocardial infarction. Hb. $4.8 \mathrm{~g} . / 100 \mathrm{ml}$., white count normal with only occasional metamyelocyte, platelets $69,000 /$ cu. mm. 12 pints blood (packed cells) given during course of next 3 weeks. Discharged in fourth week taking cyclophosphamide $50 \mathrm{mg}$. daily, prednisone $30 \mathrm{mg}$. daily. Ten days later carbuncle of face. Death 3 months after diagnosis. No necropsy.

\section{Case no. 6}

B.S. Male. Age 45. Acute myeloblastic leukaemia. Upper abdominal and left shoulder pain developing suddenly 17 days before admission. Large spleen.
Investigations: Hb. 11.2 g./100 ml., WBC 7,400/ cu. mm., occasional primitive cells, platelets $147,000 /$ cu. $\mathrm{mm}$. Slightly increased fragility of red cells, Coombs test negative. Three weeks later sternal marrow hypercellular with $53 \%$ primitive cells, platelets 87,000 .

Treatment: Cyclophosphamide $50 \mathrm{mg}$./day orally, prednisone $20 \mathrm{mg}$./day.

Progress: Rapid improvement, with return to normal health, full employment. Normal blood picture. Complete remission continues (over 12 months).

\section{Case no. 7}

J.C.R. Male, Age 31 years. Acute monocytic leukaemia (Schilling).

Sore throat for 3 weeks, lower abdominal pain for 1 week. Generalised lymphadenopathy, no splenic or hepatic enlargement.

Investigations: Hb. $12 \mathrm{~g} . / 100 \mathrm{ml}$. (but had received 5 pints blood before transfer), WBC $69,000 / \mathrm{cu}$. $\mathrm{mm}$. (23\% monoblasts), $14 \%$ monocytes), platelets $27,000 /$ cu. $\mathrm{mm}$.

Treatment: Blood (see above), cyclophosphamide $50 \mathrm{mg}$./day orally, prednisone $75 \mathrm{mg}$./day.

Progress: No improvement. Death 2 weeks after diagnosis. No necropsy.

\section{Discussion}

The fact that there were 3 cases of acute monocytic leukaemia in such a small series is explained because these patients were referred for investigation and treatment from consultant physicians in all parts of the Midlands. 


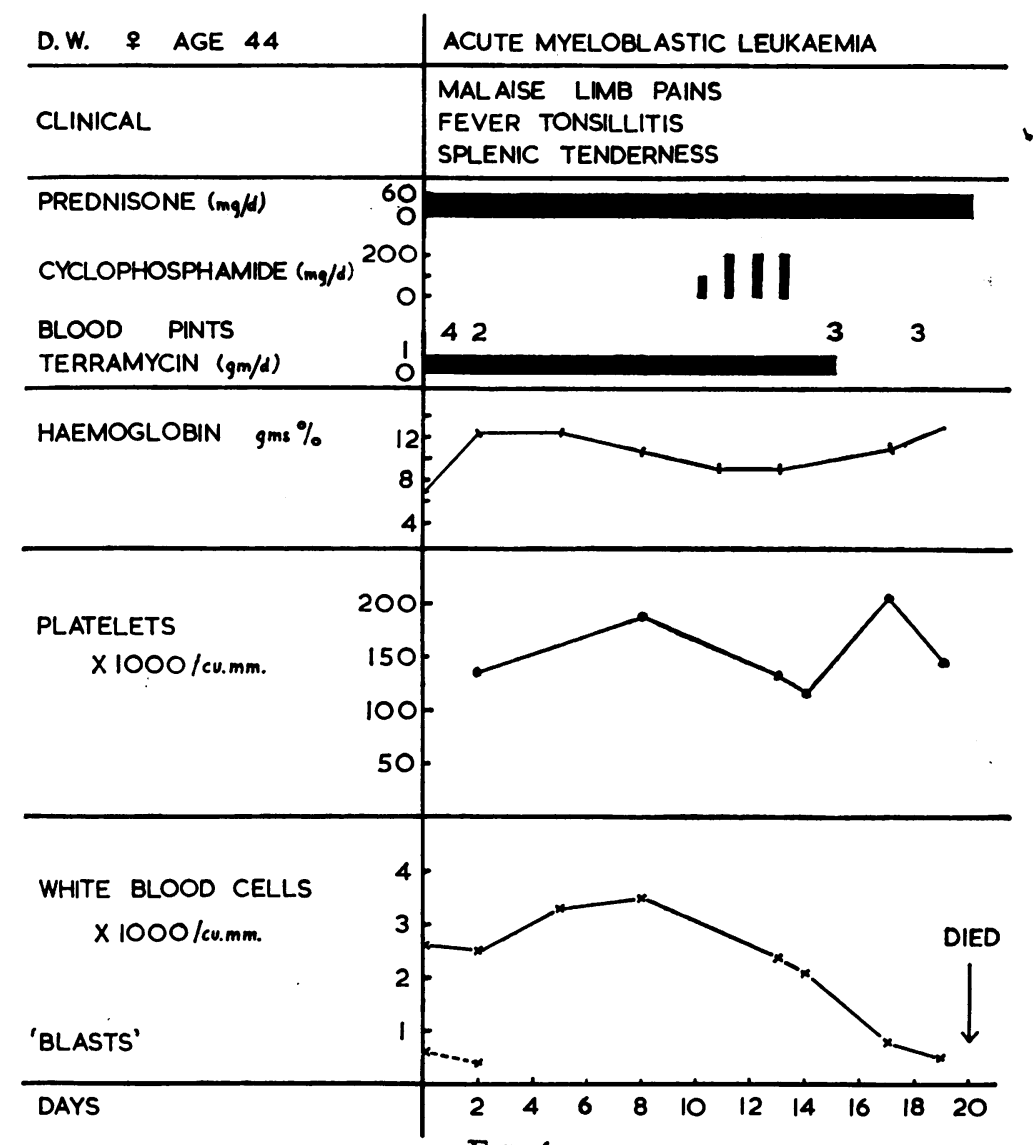

FIo. 4.

Response to treatment can be judged according to the criteria suggested by Bridges, Hayes and Nelson (1962).

$i$. Complete remission is defined as improvement sufficient for the patient to return to his former level of activity, and with a normal peripheral blood picture, including haemoglobin and platelet levels.

ii. No response means a failure to secure clinical improvement, any rise in haemoglobin level or platelet count, or a reduction by $50 \%$ in the number of circulating primitive white cells.

iii. Partial remission is an improvement, not amounting to a complete remission.

There have been reports of cyclophosphamide therapy for children with acute leukaemia. Fernbach, Sutow, Thurman and Vietti (1962) reported complete remission in 8 and partial remission in 5 of 44 children treated with this drug. In the series of 19 children treated by Sweeney, Tuttle, Etteldorf and Whittington (1962), 11 showed some improvement, includ- ing 2 with a complete remission. Hoogstraten (1962) studied 109 patients. About half of these were children, many of whom had had previous treatment. Twenty nine showed improvement, 3 having a complete remission.

Acute leukaemia in adults differs from the disease in childhood. Acute lymphatic leukaemia is rare. Survival time is shorter, second remissions are rare and failure to respond to treatment is more frequent, especially if there is a high total white count when the patient first comes under review.

Acute monocytic leukaemia (Schilling) tends to be refractory to treatment and usually runs its course in 6-8 weeks. It is consequently noteworthy that, when treated with cyclophosphamide, 2 of our cases of monocytic leukaemia had complete remissions for periods of 4 and 6 months respectively. The third patient proved completely resistant to treatment.

Of the 4 patients who had acute myeloblastic leukaemia and cyclophosphamide therapy, 1 showed a complete remission which has persisted so far for more than 14 months, 2 had 
Fig. 5.

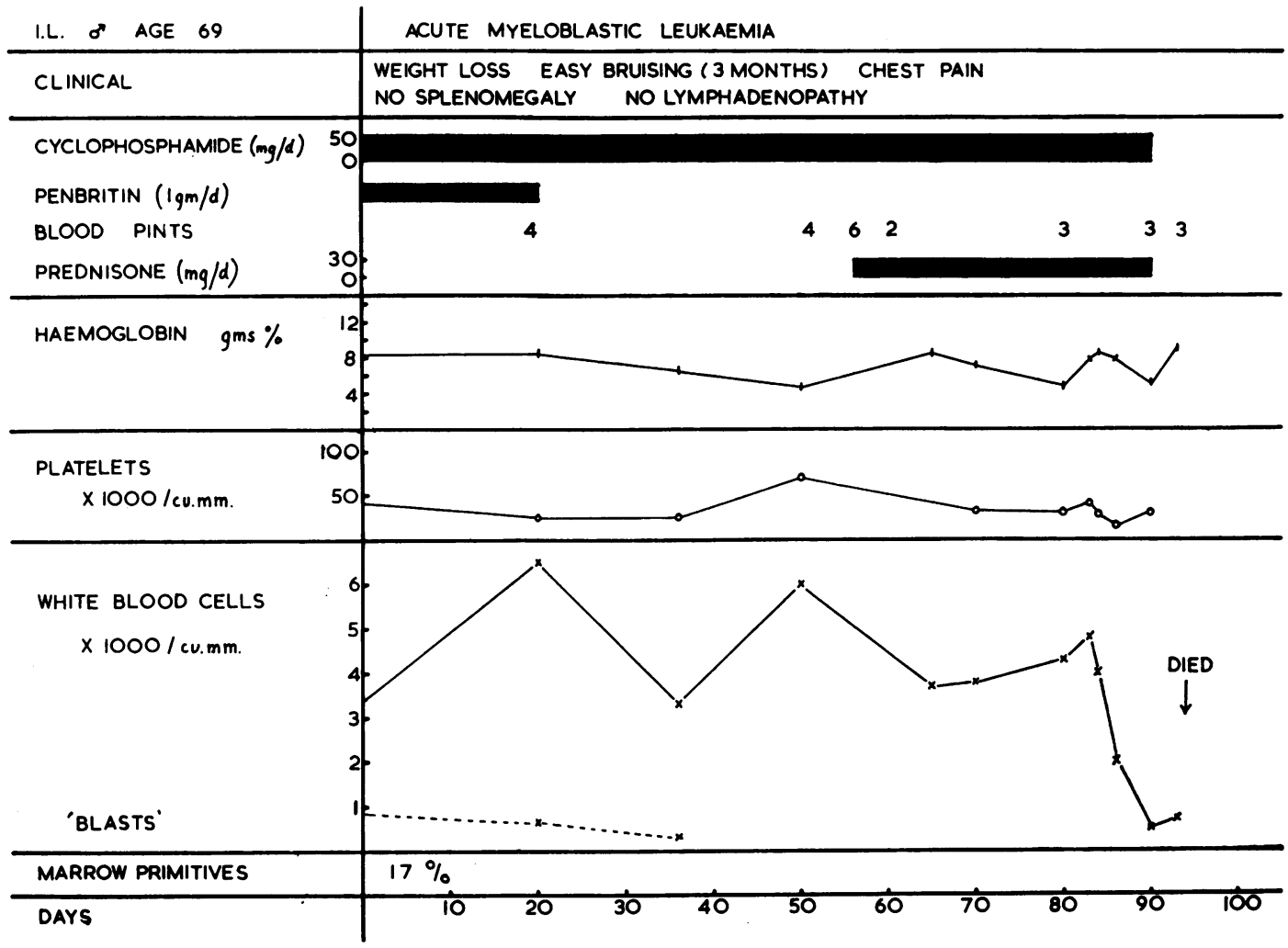

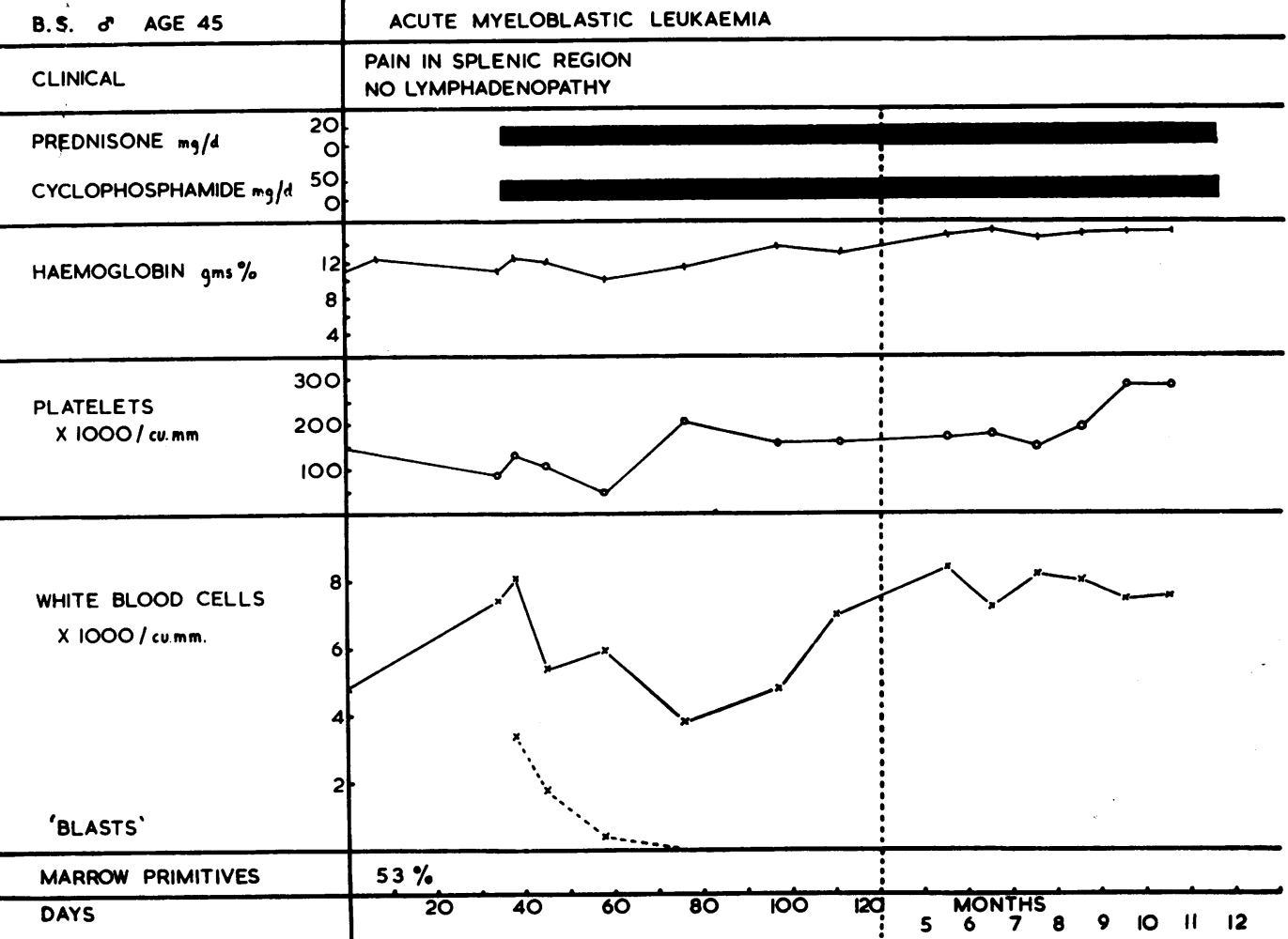

Fio. 6. 


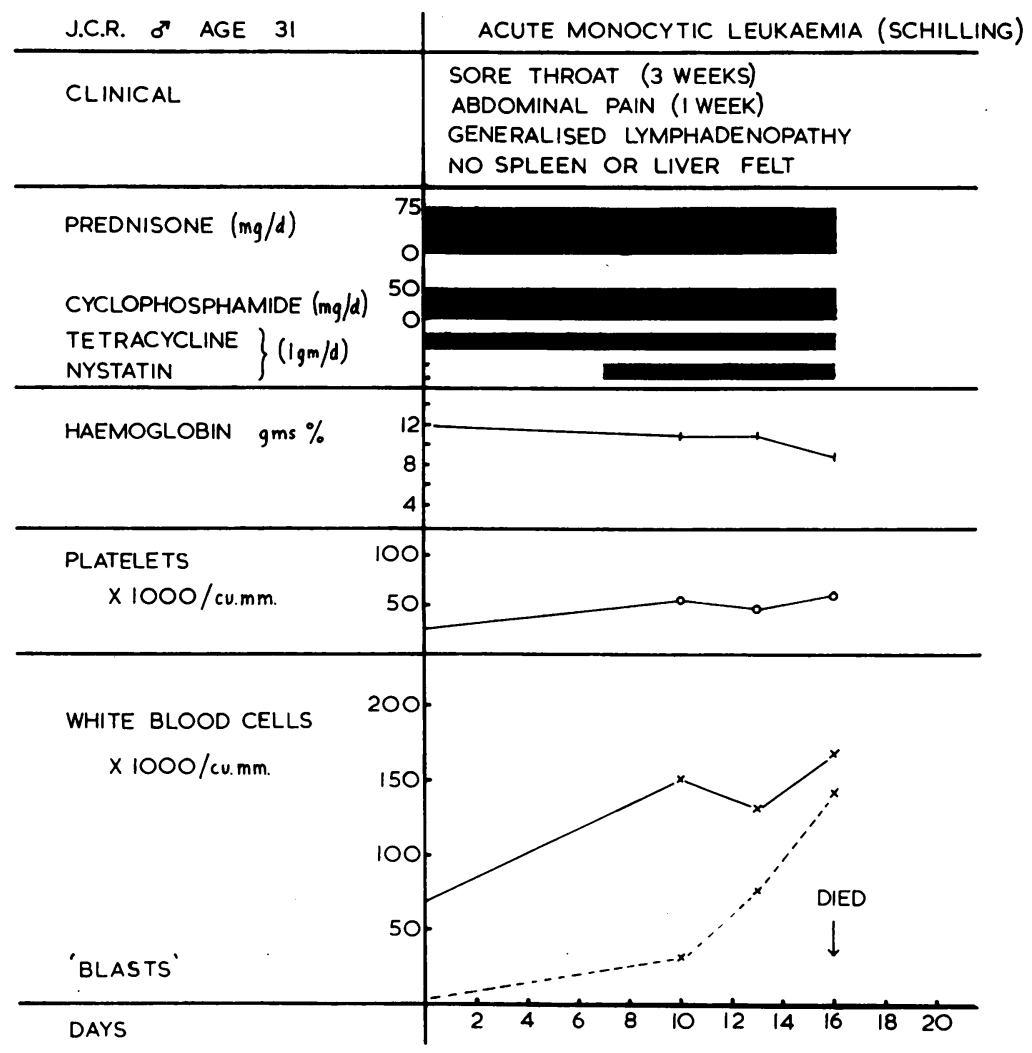

FIG. 7.

a partial remission and survived for 5 months and $2 \frac{1}{2}$ months respectively, 1 showed no response.

The general management of these patients has been kept as simple as possible. Blood counts were infrequent after the first 2 weeks, and marrow examination was avoided after diagnosis had been established. The time spent in hospital was short and the patients suffered little discomfort. Relapse, when it occurred, was of brief duration; it was uninfluenced by further treatment and death was swift.

\section{Conclusions}

Cyclophosphamide is a useful drug in the treatment of acute leukaemia in adults. It is as effective as 6-mercaptopurine and much more pleasant for the patient, especially in the early stages of treatment. The drug should be given daily throughout the illness. Stopping treatment prematurely may perhaps account for some of the relapses observed. Of three patients with acute monocytic leukaemia (Schilling) 2 had temporary complete remission of the disease. Of 4 patients with acute myeloblastic leukaemia, 1 has had a long, complete remission, 2 had temporary remissions, 1 did not respond.

\section{REFERENCES}

Bridges, J. M., Hayes, D. M., and Nelson, M. G (1962): Therapy of Acute Leukaemia: Comparison of Initial Treatment with 6-Mercaptopurine Alone and in Combination with Steroids, Brit. J. Cancer, 16, 46.

Fernbach, D. J., Sutow, W. W., Thurman, W. G., and VIETTI, T. J. (1962): Clinical Evaluation of Cyclophosphamide. A New Agent for the Treatment of Children with Acute Leukaemia, J. Amer. med. Ass., 182, 30.

Hoogstraten, B. (1962): Cyclophosphamide (Cytoxan) in Acute Leukaemia, Cancer Chemother. Abstr., No. 16, 167.

Lannigan, R., and Meynell, M. J. (1959): Moniliasis in Acute Leukaemia, J. clin. Path., 12, 157.

SweEnEY, M. J., TutTle, A. H., ETTEldorf, J. N., and WhitTington, G. L. (1962): Cyclophosphamide in the Treatment of Common Neoplastic Disease of Childhood, J. Pediat., 61, 702. 